\title{
Las normas en femenino: la construcción de identidades y su perdurabilidad en el discurso histórico. Un estudio comparativo de las reglas monásticas de Cesáreo de Arlés
}

\author{
Female rules: The construction of identities and their \\ durability throughout historical discourse. A comparative \\ study of the monastic rules of Caesarius of Arles
}

\author{
Lorena Garri Catchot \\ Universitat de Barcelona. Departament d'Història i Arqueologia. Secció d'Història Antiga i Història d'Amèrica i Àfrica. \\ Àrea d'Història Antiga \\ C/ Montalegre, 6, E-08001 Barcelona \\ Igarri@ub.edu
}

El objetivo de este artículo es ahondar en las raíces de la primera fundación monástica femenina occidental. La conservación de las dos reglas monásticas del obispo Cesáreo de Arlés nos ha brindado una valiosísima oportunidad para realizar un estudio comparativo que, juntamente con la aplicación de los instrumentos analíticos que nos proporcionan las metodologías de investigación feminista, ha arrojado nuevos datos que contribuyen a enriquecer la visión que se tiene del prístino monacato occidental femenino, así como constatar la necesaria revisión de antiguos discursos históricos con la finalidad de reinterpretarlos.

\section{PALABRAS CLAVE}

ADALBERT DE VOGÜÉ, ANTIGÜEDAD TARDíA, ASCETISMO, GÉNERO, MUJERES, REgLAS MONÁSTICAS

The aim of the following article is to explore the origins of the first western female monastic foundation. The survival of the two monastic rules laid down by bishop Caesarius of Arles has provided us a most valuable opportunity to carry out this comparative study which, together with the application of analytical tools provided by feminist research methodologies, has generated new data that contributes to both enriching the view that we have of early western female monasticism and, at the same time, underlines the need to revise and reinterpret old historical discourse on the subject.

\section{KEYWORDS}

ADALBERT DE VOGÜÉ, ASCETICISM, GENDER, LATE ANTIQUITY, MONASTIC RULES, WOMEN 
El estudio comparativo de las reglas monásticas de Cesáreo de Arlés (obispo de esta ciudad entre el 502 y el 542) tiene como finalidad conocer cuáles fueron aquellos aspectos normativos que debieron reforzarse cuando no hubo más remedio que incorporar a las mujeres en el seno de la Iglesia institucionalizada. El hecho de conocer cómo éstas fueron desenvolviéndose y acomodándose en una institución hegemónicamente masculina y en donde no había espacios reservados para ellas, continúa siendo una cuestión, a la par que clave, lagunosa; las particularidades de las fuentes históricas para el estudio del período, por el momento, dificultan cualquier intento de propuesta que vaya más allá de simples hipótesis y conjeturas.

A los silencios de las fuentes se añaden los ingredientes de unas narrativas construidas sobre la base de la ideología de una época histórica concreta que, de la misma manera que sucede en la actualidad, tenía nítidamente definidos los patrones de lo que debía ser la «mujer ideal» o «el hombre ideal» en el conjunto social, lo que por comodidad he denominado "individuo tipo (femenino o masculino)». Evidentemente, en esta diferenciación del individuo tipo, el sexo desempeña un papel fundamental. Para el caso que nos ocupa, un análisis intertextual de la producción literaria de los Padres de la Iglesia revela el diseño de una estrategia que tenía como finalidad mantener a las mujeres alejadas de los «puestos de control» de la corporación, creando lo que Elizabeth A. Clark denominó "una ideología de género" (1994).

Es por ello por lo que se analizará detenidamente la interpretación historiográfica que se ha hecho de dichas reglas en trabajos posteriores, ya sean ediciones, críticas o no, traducciones y monografías. Así pues, se pretende constatar la necesidad de revisar y deconstruir, o, si se prefiere "rehistorizar» (Clark, 1994: 178), antiguos discursos o paradigmas que nos permitan acercarnos con más justicia y precisión al momento histórico en cuestión, que pasan por la necesaria desnaturalización de las condiciones que ayudan a producir ideologías de género (Clark, 1994: 178).

Es por esta razón que el presente estudio ha incorporado la categoría analítica del género como una categoría fundamental —aunque no única- en la construcción de identidades femeninas, con la clara voluntad de poner el énfasis no tanto en la desigualdad padecida por las mujeres — obviedad manifiesta - sino más bien sobre qué criterios se fue construyendo y moldeando su identidad. Todo ello puede acercarnos a una mayor comprensión del funcionamiento social y de las relaciones entre los géneros circunscritas en los colectivos religiosos durante los siglos VI y vII, momento que Jane T. Schulenburg (1988: 103) bautizó como el Golden Age del monacato femenino en Occidente.

A pesar de la concreción de este estudio, los resultados pueden ser perfectamente extrapolables a otros casos de cenobios femeninos ubicados en el Occidente latino. No obstante, será especialmente el análisis crítico de los datos desde la teoría feminista ${ }^{1}$ lo que

1. Para más información sobre las MIF o Metodologías de Investigación Feminista, véase, entre otros, Biglia, 2015: 21-44; Guzmán y Pérez, 2005: 112-126; Anderson, 2010 [en línea]; Bartra, 2010: 67-77; Harding, 1987: 9-34. 
permitirá arrojar nuevas informaciones. Esta deconstrucción de los discursos y su posterior reinterpretación es un mérito sólo atribuible a las potencialidades que nos brindan los estudios de género y la interseccionalidad, así como los recursos que la corriente de la postmodernidad ha ofrecido y continúa ofreciendo a la disciplina histórica.

\section{Del cubiculum al coenobium}

Durante la Antigüedad tardía se produjo un momento paradójico en relación con el estatus de las mujeres religiosas. El cristianismo, en su afán de control político y social, defendió la feminidad sólo en términos de sexualidad, y para ello se definió una nomenclatura concreta: virgen, casada o viuda, a la vez que ofrecía a las mujeres nuevos espacios de poder como el cenobio, que permitieron, de forma gradual, ir abandonando los enclaves de religiosidad doméstica más o menos informales Éste podía ser el caso del cubiculum, es decir, aquella estancia de la domus romana que durante la Antigüedad tardía fue asociándose de forma progresiva al lugar donde tenían lugar las experiencias espirituales con Dios (Sessa, 2007: 180-181).

Como se acaba de apuntar, esta progresiva incorporación al mundo de la oficialidad eclesiástica concedió poder a las mujeres, aunque éste se escaparía de la forma oficial y no sería ni legítimo ni directo, sino una especie de "poder en la sombra» (Mirón, 2010: 117118), a modo de influencia pública o influencia sobre el mismo poder, contrarrestando su ausencia en la esfera política. No obstante, no se debe perder de vista que, en última instancia, este tipo de mujeres estuvieron siempre tuteladas por una figura masculina.

Fue entonces, a partir de mediados del siglo IV, pero especialmente durante las dos siguientes centurias, que se produjo un momento de crecimiento importante de fundaciones religiosas exclusivamente femeninas. En este contexto, las instancias religiosas no tuvieron más remedio que dar cabida a los desafíos que la nueva realidad les estaba planteando: las mujeres debían ocupar espacios hasta el momento no reservados ni pensados para ellas, que, entre otras muchas cosas, se materializarían en una mayor visibilidad y protagonismo social, y que, en definitiva, podían poner en jaque los mecanismos de control masculino sobre ellas. La incorporación de las mujeres al mundo de la oficialidad cristiana contradecía todas aquellas normas de comportamiento social, y, en suma, el paradigma identitario femenino definido por cuestiones exclusivamente sexuales.

En definitiva, la progresiva difusión del cristianismo y el triunfo del ideal ascético pronto dieron lugar a una presencia cada vez más frecuente de las mujeres en la esfera pública; como contrapartida, esto motivó una serie de cambios orgánicos en el seno de las instituciones religiosas, que pasaron por un necesario reforzamiento de la ideología de género y del afianzamiento de las identidades femeninas, a fin de dar respuesta a todas aquellas acciones o circunstancias que pudieran hacer tambalear los principios sobre los cuales se asentaba la hegemónica posición masculina. 
Durante los siglos IV a VII hubo una proliferación de fundaciones monásticas femeninas especialmente importante en el sur de la Galia, una tendencia parece ser que iniciada de la mano de Martín de Tours (Schulenburg, 1989: 264); un fenómeno que de manera ascendente y progresiva continuó expandiéndose hacia los territorios de Germania y Britania. Este acontecimiento en expansión contribuyó a un puntual momento de protagonismo femenino generalizado, dando lugar a un modelo religioso que difería tanto de patrones precedentes como posteriores, y que sirvió para asentar las bases del futuro paradigma monástico medieval.

La mayor presencia de instituciones religiosas propiamente femeninas permitió a las mujeres - a pesar de estar sujetas a una regla — gozar de más libertades que sus predecesoras en Occidente, quienes practicaron una religiosidad, sobre todo, de tipo doméstico. Todo ello no equivale a presuponer que los monasterios fueran en el siglo vi unos auténticos oasis de libertad, sino que lo que hubo fue la posibilidad de que las mujeres ejercieran un poder fáctico con capacidad de injerencia en múltiples aspectos. Esta consecución de poder fue posible por diversas razones, aunque clarísimamente no se podría haber producido si el siglo vi no hubiera sido un momento de una ostensible debilidad y descentralización de la autoridad real y eclesiástica. Muy probablemente, y también aprovechándose de esta coyuntura, las mujeres que sí gozaron de una mayor autonomía fueron aquellas que se encontraban fuera del sistema, es decir, aquellas que no participaban de las formas de espiritualidad "ortodoxas" e institucionales, sino que optaban por vivir de manera consciente en los márgenes, transgrediendo tanto la ideología de género como el prototipo de perfecta cristiana, motivo por el que eran duramente perseguidas y castigadas.

Esta debilidad institucional claramente favoreció la existencia de una especie de «vacíos de poder» que las mujeres, ya fuera desde la oficialidad o desde la marginalidad, supieron aprovechar y ocupar, unos espacios que quedaron vacantes en el contexto de los cambios estructurales que se estaban produciendo a raíz de la definitiva disolución política del Imperio romano de Occidente.

Parece entonces que se puede retomar aquí aquella teoría apuntada por la historiadora Joan Kelly en su célebre artículo Did Women have a Renaissance? de 1977, según la cual no hubo un renacimiento ${ }^{2}$ real para las mujeres, o no al menos durante el Renacimiento, ya que éste les afectó de manera negativa, experimentando «una contracción en las opciones sociales y personales que los hombres de sus mismas clases no sufrieron» (Kelly, 1990: 93-94). Lo que Joan Kelly y otras autoras pudieron y continúan constatando es que, ciertamente, en las épocas de mayor trascendencia y esplendor para la historia de la humanidad, las mujeres han visto retraída su libertad (en el sentido más amplio del término), mientras que realmente viven su momento de esplendor en las épocas de crisis y de colapso, como sucedió con las mujeres bajomedievales, tenedoras de feudos y que actuaban con autoridad señorial sobre los mismos (Kelly, 1990: 102-103), ya fueran laicas o religiosas (abadesas); lógico, si tenemos en cuenta que el sistema fallido, el que decae, es androcéntrico y patriarcal.

2. En minúscula, siendo fiel al doble juego que plantea la autora. 


\section{Cesáreo de Arlés: una regla para mujeres, otra para hombres}

El obispo Cesáreo de Arlés ha pasado a la historia como el exponente del paradigma del obispo-monje; ya en su época, sus cualidades como predicador, pastor y reformador, acérrimo defensor de la obediencia y la pobreza, pronto le proporcionaron su merecida fama. Personaje claramente influenciado por las tesis de Agustín de Hipona — se estima que en un 31 \% de su obra (Courreau y Vogüé, 1994: 24) - y conocedor de las principales obras patrísticas y ascéticas, tanto orientales - Basilio de Cesarea o Pacomio- como occidentales -el propio Agustín, Juan Casiano o la Regula SS. Serapionis, Macarii, Paphnutii et alterius Macarii, entre otros-, que le concedieron la sólida base intelectual que conformó su pensamiento y determinó su obra. Indiscutiblemente, su formación como asceta en la abadía de Lérins fue fundamental, así como excepcional fue su capacidad retórica, que le permitió dirigirse a un amplio abanico de audiencias, simplificando y codificando un mensaje hasta entonces ininteligible para el vulgo (Klingshirn, 1994: 81).

Ante la considerable demanda que hubo por parte de las mujeres para engrosar las filas de la Iglesia, independientemente de la relación de causas que la motivara, Cesáreo estuvo muy prontamente interesado en hacerla realidad y crear una comunidad monástica femenina, del mismo modo que hicieron algunos de sus predecesores en Occidente, caso de los obispos Ambrosio de Milán, Agustín de Hipona o Martín de Tours, entre otros; de hecho, su Vita nos relata que a través de un mandato divino dotó de protección a la ciudad con un grupo de innumerables clérigos y un coro de vírgenes (Cypr., Firm. et Viu., Vita, I, 28: 184). Las ventajas de contar con fundaciones de estas características eran, ya en aquel entonces, considerables, ya que, a pesar de la pretendida ingenuidad de los biógrafos del prelado arelatense, no hay que desdeñar el rédito económico que suponía la presencia de un monasterio de vírgenes en la urbe, así como el enorme prestigio que le reportaría al obispo, quien ejercería su eterno tutelaje, incluso después de la muerte; no olvidemos que Cesáreo escogió como lugar de reposo eterno el ábside de la basílica de Santa María, junto con su hermana y su comunidad femenina y no entre sus iguales masculinos (Cypr., Firm. et Viu., Vita, I, 28: 184), convirtiendo el lugar en un emplazamiento sagrado y de peregrinaje, una moda que a posteriori siguieron los obispos de Sevilla, Leandro e Isidoro.

Parece ser que hubo una primera fundación del monasterio de San Juan de Arlés después del Concilio de Agde del 506, una posibilidad que se deduce a partir de la lectura de su canon 28, donde se regula la distancia que debía haber entre los monasterios femeninos y los masculinos: "monasteria puellarum longius a monasteriis monachorum, aut propter insidias diaboli aut propter oblocutiones hominem collocentur» (Conc. Agath., 28: 205). De este primer núcleo formarían parte un grupo de mujeres ascetas, que vivirían bajo la dirección espiritual de Cesárea la Mayor, la hermana del obispo, probablemente en un monasterio de tipo familiar (Klingshirn, 1994: 104). Esta primera fundación se conoce gracias a la información contenida en la epístola Vereor que Cesáreo envió a su hermana. Este monasterio 
no duró mucho tiempo, pues fue destruido por una invasión francoburgundia entre los años 507 y 508. El obispo no cejó en su empeño y erigió nuevamente el cenobio, esta vez protegiéndolo intra muros y consagrándolo el 26 de agosto del año 512 bajo el patronazgo de san Juan Bautista.

A pesar de que tanto en Oriente como en Occidente hubiera ya una prolífica literatura moralizante, así como una cierta legislación en lo que atañía a vírgenes, viudas y casadas - ya fuera a través de tratados, epístolas o breves normativas, que Cesáreo no sólo conocía, sino que además reprodujo a conveniencia-, aquellas recomendaciones del ideal monástico no se institucionalizaron plenamente en forma de norma hasta la promulgación de la Regula sanctarum uirginum en el 534, la primera conocida de este tipo ${ }^{3}$.

De hecho, el propio Cesáreo da clara cuenta de la necesidad de una legislación adaptada a "su sexo", pecador, débil, incapaz y dependiente por naturaleza: "et quia multa in monasteriis puellarum ac monachorum instituta distare uidentur, elegimus pauca de pluribus, quibus seniores cum iunioribus regulariter uiuant et spiritaliter implere contendant, quod specialiter suo sexui aptum esse prospexerint» (Caes. Arel., Reg. uirg., 2: 180). Según sus propias palabras, parece ser que tuvo claro desde el principio que una aplicación reversible de la normativa masculina de la vida en comunidad sería impracticable e incluso arriesgada; por lo tanto, precisó de una regulación ad hoc clara, precisa y contundente. Esta normativa fue en la línea de blindar el ideal de la mujer cristiana, reforzando los roles prescritos a mujeres.

Estos roles, actitudes e identidades genéricas no eran nuevas, sino herederas de una moral con una larga tradición misógina, anclada en las sociedades antiguas y reproducida con éxito por el cristianismo. La inclusión de las mujeres en este nuevo escenario, saliéndose del patrón común de pequeños grupos de espiritualidad doméstica y mayoritariamente privada, hizo trastabillar los cimientos de una Iglesia (y, en definitiva, de toda una sociedad) que se encontraba en pleno proceso de cambio; lógico, si tenemos en cuenta que, cuando las mujeres salen de sus espacios y adoptan papeles sociales que no son los suyos, no tienen medida, son incontrolables y rompen con la harmonía creada o pactada (Martínez, 2006: 163). Era, pues, preciso legislar cuanto antes.

\section{Un mismo texto, diferentes interpretaciones}

La conservación casi en su completa integridad de la Regula sanctarum uirginum (ca. 512 534) y la Regula monachorum (ca. 534-542) es de gran utilidad para aquellos estudios que tienen como principal prioridad la identificación de las diferencias entre los sexos, dado que ello nos permite reafirmar la existencia de situaciones de desigualdad a través de ejemplos

3. No obstante, la regla estuvo vigente, aunque en constante evolución, desde el 512, cuando se entregó la primera parte a la abadesa Cesárea. Los veintidós años que pasaron hasta su promulgación definitiva permiten hacernos una idea tanto de lo novedoso como de lo complejo de la situación. 
concretos y, a su vez, traer a colación formas de vida, actitudes, identidades y relaciones jerárquicas entre hombres y mujeres, y conocer cómo éstas fueron entretejiéndose en un momento concreto del pasado. Baste mencionar como ejemplo el léxico utilizado en el título de ambos textos, Regula monachorum (regla de los monjes) y Regula sanctarum uirginum (regla de las santas vírgenes), que nos remite a su carácter sacrosanto y, además, a su estatus sexual. Como puede observarse, no hay atisbos de ingenuidad en el vocabulario utilizado ni por Cesáreo ni por sus predecesores.

A la problemática inherente a las fuentes disponibles para el estudio del mundo antiguo, como puede ser la fragmentación, la parcialidad o la falta de testimonios femeninos directos, se le añade la particularidad de su androcentrismo generalizado; nos encontramos con unos discursos que no sólo habían sido escritos por hombres, sino que lo escrito sobre las mujeres había sido redactado sobre la base de la posición de dominio masculino y conforme a la idea preestablecida de lo que convencionalmente se esperaba que fuesen sus compañeras femeninas.

Como se ha venido apuntando, el mecanismo o técnica de análisis que nos permitirá rastrear las posiciones de unos respecto a otras será, primero, a través de la comparación de las dos reglas monásticas de Cesáreo ${ }^{4} \mathrm{y}$, segundo, a partir de los estudios recogidos en las ediciones críticas de las mismas, elaborados a cargo de Adalbert de Vogüé, uno de los mayores conocedores de la vida y obra de Cesáreo, con la colaboración de Joël Courreau, quien tradujo otros documentos contenidos en dichos volúmenes para la colección de Sources Chrétiennes (1994, 1998).

Los nuevos datos interpretativos deben sumarse a las aportaciones anteriores, pero también permitirán matizarlas siempre que resulte preciso. Así, por ejemplo, la existencia de relaciones de desigualdad entre ambas regulaciones ya fue intuida por el propio Adalbert de Vogüé —él refiere diferencias y no relaciones de desigualdad, obviamente-, aunque, sin embargo, éstas fueron malinterpretadas fruto de la mentalidad de la época, agravada por un positivismo académico y androcéntrico que para entonces aquejaba a la disciplina e invisibilizaba a las mujeres. No obstante, Adalbert de Vogüé tiene el mérito de haber desmentido la teoría de la primogenitura de la regla masculina; así pues, no fue la masculina la que inspiró la redacción de la femenina, sino todo lo contrario (Vogüé, 1971, 1994). En realidad, la regla masculina sería un mero resumen, no dirigida a ninguna comunidad concreta y focalizada básicamente en los principios de la caridad fraternal, el perdón y la lucha espiritual.

Gracias a la incorporación de un análisis crítico y con perspectiva de género, y pese a no disponer de testimonios femeninos directos, se podrá plantear una aproximación a la situación social, política y jurídica de estas mujeres del siglo vI, que, aunque invisibles en el discurso oficial, fueron parte indispensable y fundamental del devenir histórico. La vida en comunidad, ya fuera por imposición o por iniciativa propia, facilitó a las mujeres la ocasión

4. Esta comparativa también podría hacerse con otros documentos análogos, como son la epístola Vereor y los Sermones 233 a 238 de Cesáreo, que aquí no podemos atender por una cuestión de síntesis. 
de hacerse con el control efectivo de su sexualidad, ocupar espacios de poder que antes les eran totalmente vetados, así como de librarse, en parte, del tutelaje masculino; y es en parte, porque este tutelaje se continuó ejerciendo a través de un paternalismo espiritual sobre las congregaciones femeninas por parte de obispos o reyes.

El mismo Adalbert de Vogüé, y otros antes que él ${ }^{5}$, se empeñaron en encontrar similitudes y diferencias entre ambos textos normativos. A pesar de la época en que realizó sus investigaciones y de su formación de carácter religioso, su análisis ya deja entrever las desigualdades latentes que tenían lugar entre hombres y mujeres (Vogüé, 1994: 170). El principal problema es que éstas no eran cuestionadas, sino que formaban parte de lo que se entendía como «lo normal», ya que era «lo natural». Por ejemplo, Adalbert de Vogüé dio cuenta del lenguaje directo y personal con tintes afectivos que desprendía el texto femenino, único en su género, y, como ya se ha apuntado líneas más arriba, de la primacía de la regla femenina respecto a la masculina (Vogüé, 1971).

Ahora bien, en ciertos aspectos y sin pretender menoscabar la transcendencia, así como la importancia de la obra del historiador benedictino, se hace preciso matizar algunas de sus afirmaciones, lo cual nos conducirá a conclusiones discrepantes. Así pues, en los casos que a continuación se exponen, él mismo interpretó que «la Règle masculine se montre plus exigeante que l'autre» —la femenina- (Courreau y Vogüé, 1994: 189), teóricamente más liviana y laxa.

En este análisis es fundamental no perder de vista que el editor utilizó el vocablo exigencia para referirse, por un lado, a que la legislación cesariana tuvo especial cuidado de la sensibilidad y delicadeza que se presuponía a las mujeres, y, por otro, (implícitamente) a que los hombres — de acuerdo con el modelo de masculinidad dominante- estaban sometidos a una observancia más severa. Sorprendentemente, fue el propio Adalbert de Vogüé quien resaltó la envergadura del texto femenino, que, recordemos, dispone de 73 capítulos en su versión final, frente a los 26 del texto masculino; por lo tanto, se trataba de un texto sin parangón, ya que, hasta el momento, la tradición monástica no había superado las cuatro páginas de extensión (Vogüé, 1985: 16-17). En este sentido, cabría reflexionar sobre esta cuestión, dado que, ¿cómo puede ser posible que una regla tan generalista y sumaria pueda considerarse más exigente que un corpus, no sólo insólito, sino extenso y preciso, como lo es la regla femenina?

Volviendo al trabajo del historiador benedictino, lo que le faltó a su análisis fue la desnaturalización de estas «exigencias»; sólo así se podrían haber reconocido las relaciones

5. Germain Morin, editor de la Regula, de las epístolas Vereor y O Profundum, la carta de Hormisdas, el Testamentum, la Regula monachorum y sus Sermones (Morin, 1942). Marie-José Delage también editó su obra, concretamente sus Sermones (Delage, 1971) y su Vita (2010). Respecto a algunas de las ediciones críticas y traducciones, contamos con las de Maria C. McCarthy, que presenta una edición crítica y traducción de la Regula al inglés, con un interesante capítulo dedicado a los trabajos de Germain Morin (McCarthy, 1960). Otra edición fue la de Cyrille Voguel, quien tradujo la Regula uirginum al francés (Voguel, 1964); más reciente fue la de Vincent Desprez, con las ediciones críticas de la Regula uirginum y de la Regula monachorum y sus respectivas traducciones al francés (Desprez, 1980). Un año después, apareció la traducción italiana de la Regula uirginum de Giuseppe Turbessi (Turbessi, 1974). 
de marginación y desigualdad que tras de sí se ocultaban, evidenciando cuáles eran las identidades y los roles de género preestablecidos e impuestos tanto para mujeres como para hombres.

Ahora bien, ¿fue esa falta de exigence para el caso femenino una clara ventaja, o por el contrario fue realmente aquello que las perjudicó y las mantuvo subordinadas y en clara desventaja respecto a sus supuestos iguales? Pongamos algunos ejemplos:

1) El tiempo que se dedica a la lectura de los textos sagrados es de dos horas para las mujeres (Caes. Arel., Reg. uirg., 19: 192) y de tres horas en el caso de los hombres (Caes. Arel., Reg. mon., 14: 214). A pesar de que ellas vieron reducido su tiempo de formación intelectual, Adalbert de Vogüé lo interpretó como una ventaja respecto a sus compañeros, ya que así podrían invertir ese tiempo sobrante en tejer la lana o en otras tareas convenientes a su sexo.

2) En referencia al castigo corporal, y siempre según la interpretación del editor, da la impresión de que se trate de algo mayoritariamente aplicable a los hombres, cosa que no es de extrañar, dado que se identifica claramente con los valores que se asocian a la masculinidad. Sin embargo, si consultamos las citas a las que el propio Adalbert de Vogüé nos remite, la cosa es bien distinta: éste arguyó que los castigos corporales no eran impuestos por delitos de naturaleza semejante en ambos sexos; en consecuencia, se prescribían en caso de mentira a los hombres y en caso de robo y pelea con puñetazos a las mujeres (Courreau y Vogüé, 1994: 190), y para ello remite al lector a Caes. Arel., Reg. mon., 5: 208 y a Caes. Arel., Reg. uirg., 26, 1-6: 204. Ahora bien, en esta primera disposición (la masculina) únicamente se lee: "mentire qui inuentus fuerit, disciplinam legitimam accipiat», es decir, que aquel que mienta recibirá la disciplina prevista, sin especificar castigo, mientras que en la segunda, la de las mujeres, se lee: "[...] necesse est enim ut in eis impleatur illud, quod de in disciplinatis filiis per Salomonem praedixit spiritus sanctus: qui diligit filum suum, assiduat illi flagellum», es decir, es conveniente aplicar aquello que el Espíritu Santo prescribió a Salomón en el caso de niños indisciplinados: quien quiere a sus hijos, los azota asiduamente; se observa cómo es realmente sólo en la femenina en la que se explicita el tipo de castigo.

Cabría preguntarse por qué Adalbert de Vogüé sólo interpretó la imposición del azote en los casos en los que la documentación se refiere a la "disciplina prevista», caso del texto masculino, y no cuando leemos "se reprimirá a la infractora como ella se merece» o «recibirá el castigo más severo según los estatutos del monasterio", caso del texto femenino, como por ejemplo en Caes. Arel., Reg. uirg., 25: 202: "si autem celans proditur uel conuincitur, secundum statuta monasterii grauius emendetur"; en 30, 3: 208: "quaecumque autem hoc fecerit, grauissimam districtionem sustineat»; así como en 43, 4: 226: "[...] non solum districtionem monasterii grauissimam sustinebunt».

Si atendemos a la lógica del historiador benedictino, ¿se puede afirmar con rotundidad, pues, que cada vez que no se explicita castigo corporal en el texto femenino (que es en la mayoría de los casos) no se hubiera ejercido violencia contra las mujeres? El simple hecho de que no haya paridad en mismas faltas y mismos castigos o que estos últimos se expliciten 
en mayor medida en la regla masculina — como podían ser los golpes de férula sobre las manos al llegar tarde al oficio (Caes. Arel., Reg. mon., 11, 2-3: 210)—no prueba, en absoluto, que la violencia fuera más recurrente en el caso de los hombres que en el de las mujeres.

3) Un último caso en el que, supuestamente, Adalbert de Vogüé vio una mayor «exigencia» $y$, por lo tanto, una situación más desfavorable hacia los frailes que hacia las freilas fue en lo relativo a la práctica del régimen de excomunión. No se debe perder de vista que en estos momentos la materialización de este tipo de penas intra coenobium difiere ligeramente del que se acostumbra a entender cuando se habla de excomunión en términos generales, ya que en muchos casos se sobreentiende como sinónimo de expulsión.

Dado que era muy improbable — aunque posible- que un hombre abandonara el monasterio, e imposible en el caso de las mujeres, la solución fue la de apartar temporalmente a los hermanos y hermanas discordantes de la comunidad. La forma y el tiempo en que esta ausencia temporal se produjo tampoco escaparon a las distinciones sexuales entre los individuos.

Remitámonos nuevamente al texto: mientras que en los documentos se utiliza la expresión resideat (Caes. Arel., Reg. uirg., 34, 1: 214), que significa 'morar', 'permanecer', para las mujeres, se utiliza reclaudatur (Caes. Arel., Reg. mon., 23: 222) para los hombres, que según Adalbert de Vogüé tiene una connotación mayor de confinamiento o reclusión (1998: 190). De acuerdo con la información que se extrae de la documentación, ellas estarían acompañadas de una hermana y deberían hacer penitencia, mientras que ellos tendrían el acompañamiento de un anciano y se dedicarían a la lectura. ¿Fueron entonces, nuevamente, las diferencias connotativas entre resideat o reclaudatur -fruto de la edulcoración del lenguaje del obispo- lo que llevó a nuestro editor a concluir que los términos de excomunión fueran más severos para unos que para otras? No parece que hubiera distinción más allá del lugar donde se producía la separación física de la comunidad, así como en el tipo y en la forma de castigo: penitencia frente a lectura.

Ahora bien, todo parece indicar que las mujeres sí gozaron de ciertas situaciones ventajosas en determinados aspectos, y uno de ellos fue en el caso del acometimiento de delitos graves que podrían haber supuesto la excomunión total. En este caso sería interesante plantear qué hubiera sucedido en los casos que revistieran más gravedad: ¿cuál hubiera sido el castigo para las infractoras y cómo se hubiera podido materializar si en ningún caso se contemplaba la posibilidad de vivir extra coenobium? Aquí, nuevamente, vuelve a darse una situación paradójica: según la documentación, la excomunión femenina en ningún caso equivalía a la expulsión del monasterio (Caes. Arel., Reg. uirg., 2: 180), cosa que proporcionaba a las posibles infractoras una cierta tranquilidad, ya que los muros del cenobio serían su morada hasta el fin de sus días, prestándoles cobijo y protección; ahora bien, el varapalo se producía cuando la prohibición de no abandonar su morada, excepto en caso de fallecer, eliminaba cualquier anhelo de revocar sus votos, o, como suele decirse, de colgar el hábito.

Para los hombres, en cambio, en una regla tan generalista como la suya y no estando sujetos a una clausura tan férrea, o tan explícitamente reglada, cabría pensar en la posi- 
bilidad de que algunos hubieran sido expulsados de manera definitiva en caso de falta muy grave. Este hecho es plausible si tenemos en cuenta disposiciones precedentes (tanto femeninas como masculinas) que atestiguan esta práctica, como, por ejemplo, la de Agustín para su cenobio femenino en Hipona (Villegas, 2011 : 282) o Benito de Nursia (Ben. Abb., Reg.mon., 58, 28: 632; 61, 8: 638; 62, 10:642; 65, 21:658; 71, 9:668); y, en el caso de regulaciones posteriores, la Regula communis atribuida a Fructuoso de Braga contempla la expulsión para casos insalvables: "quod si abusiue habuerit monachorum praecepta et hanc secundo geminauerit culpam, uerberatus denuo carcere mancipetur; aut si paenitere noluerit, foras proiciatur» (Ps.-Fruct. Brac., Reg. com., 15: 199-200).

Si este hubiera sido el caso de los monjes de Cesáreo, los hombres habrían dispuesto de una especie de «mecanismo legal» para abandonar la vida ascética, una posibilidad totalmente inalcanzable para sus compañeras.

A pesar de estas divergencias interpretativas, Adalbert de Vogüé (1994: 189) también convino en que sí hubo aspectos en los que las mujeres se vieron claramente más favorecidas que sus compañeros, como fue en el caso de la severidad en los ayunos (Caes. Arel., Reg. mon., 22: 220). Precisamente, a causa de su supuesta debilidad, entre Pentecostés y las kalendae de septiembre la abadesa era la encargada de decidir la manera de ayunar, por lo que recibía así un poder del que no disponía su homólogo masculino (Caes. Arel., Reg. uirg., $67,1: 258)$. No obstante, la existencia de este supuesto "trato de favor» debe ser motivo de análisis, y, de hecho, así es, dado que nos proporciona información sobre algunas de las particularidades que conformaron parte de la ideología de género de entonces y con las que hubieron de comulgar el colectivo de mujeres que se dedicaron a la espiritualidad institucional en los siglos v y vi.

Los dos únicos aspectos en los que Adalbert de Vogüé observó ciertas desventajas para con las mujeres fueron, por un lado, la existencia de la estancia del salutatorium (Caes. Arel., Reg. uirg., 346: 214-216; 38: 220; 58: 242; 65: 250-252), y por otro, la exigencia de una férrea castidad, sólo asumible a través de la imposición de un contundente régimen de clausura (Vogüé, 1994: 190-191).

En cuanto al salutatorium, se trataba de una especie de sala multifuncional, totalmente vigilada y parece ser que construida ad eas; esta estancia era el nexo de unión con el exterior y, por lo tanto, servía de lugar de acceso, supervisado por la abadesa y sus escoltas. Entre sus usos más frecuentes era mayoritariamente utilizada para excomulgar, recibir visitas, cumplir castigos, o para que las novicias moraran durante el primer año de ingreso; una vez pasado este periodo, podrían tomar el hábito, siempre y cuando la abadesa lo considerara oportuno (Caes. Arel., Reg. uirg., 4, 2: 182). Ni en la regla masculina de Cesáreo ni en las de sus sucesores se contempla este lugar —al menos, no con este nombre-, poniendo de manifiesto la sexualización de los espacios también en el caso de los primeros monasterios. La ausencia de esta sala nos conduce a una conjetura importante: si no era requerida la permanencia de los hombres en una estancia concreta del conjunto

6. Aquí no se menciona el salutatorium, pero podemos deducir que se estaría refiriendo a él. 
monástico, como podría ser el salutatorium, y, además, no se tiene constancia de ningún espacio similar, es muy posible creer que tanto esta sala, así como el tiempo en que en ella debían morar las novicias, formarían parte de una especie de ritual de purificación, de limpieza del pecado, que iba intrínsecamente asociado a la idea de mujer, y, por lo tanto, que se hubiera tratado de una zona exclusivamente femenina.

Con todo, y a pesar de que el editor considerara la existencia y el uso de esta sala como algo desventajoso para las mujeres, rápidamente matizó, relativizó e, incluso, valoró su funcionalidad arguyendo que «l'attente d'une année favorisait la liberté des candidats, qui pouvaient s'engager en meilleure connaissance de cause» (Vogüé, 1994: 191), a sabiendas de que, en realidad, no pudieran desdecirse y abandonar el cenobio.

\section{Cosas de y para mujeres: la clausura extrema}

La significación del concepto de clausura es versátil, es decir, sus acepciones pueden ser positivas o negativas en función del contexto. Aquí, se ha tomado en su acepción más «represiva», concretamente por dos motivos: en primer lugar, porque la normativa no es fruto de una voluntad de autoorganización o de autoimposición de normas ascéticas por parte de las propias novicias, sino que es creada para ellas y, en consecuencia, difiere mucho de ser igualitaria respecto a la de sus compañeros; en segundo lugar, porque la imposición de una norma siempre suele ir asociada a una idea negativa. Las hipotéticas ventajas que, en términos generales, su encierro pudiera acarrearles es otra cuestión y uno de los grandes temas de estudio y debate sobre las comunidades monásticas femeninas; para nuestra cronología concreta consideramos que está por hacerse una investigación minuciosa acerca de si el uso instrumental que se hizo de la clausura por parte de los hombres equivalió en estas primeras comunidades occidentales a una situación mayoritariamente liberadora o si, por el contrario, se convirtió en un lugar de castigo y auténtica represión.

El régimen de clausura extrema al que nos hemos referido unas líneas más arriba fue uno de los aspectos en los que Adalbert de Vogüé (1998: 191) observó un mayor perjuicio hacia las mujeres, pues la clausura impuesta en el monasterio de San Juan fue muy rigurosa en comparación, por ejemplo, con la que estipula la Regula communis, atribuida a Fructuoso de Braga, la cual, a diferencia de la arelatense, sí contemplaba en su capítulo 15 la expulsión del cenobio (Rivera, 1989: 25). Se observa cómo el recordatorio de su cumplimiento a las vírgenes es constante a lo largo del texto (Caes. Arel., Reg. uirg., 2: 180; 3: 182; 36, 6: 220; 37: 220; 50: 236; 70: 266-268; 73:272).

Ahora bien, de la misma manera que en el caso anterior y aun habiendo reconocido su trato desigual, el editor optó por restar importancia a la cuestión de la clausura, hasta el punto de llegar a justificarla, formulándose la siguiente pregunta: "A elle seule, cette différence ne compense-t-elle pas, au moins à nos yeux de modernes, tous les accroisse- 
ments de rigueur qu'on observe en passant d'une Règle à l'autre?» (Vogüé 1994: 191). La dureza y el rigor supuestamente aplicados a los hombres justificaban a todas luces la férrea disciplina impuesta a mujeres, focalizada en la represión de su sexualidad.

La exigencia de rigurosas formas de clausura, como las que impuso el prelado arelatense sobre la comunidad femenina, había sido hasta entonces poco común en las disposiciones precedentes de la latinidad occidental; para citar otro caso similar, podemos referirnos al caso de las ciento cinco monjas de La Balme, que también practicaban una severa clausura: "tanta namque ills temporibus inibi districtio seuabatur, ut, quaecumque uirginum illic causa abrenuntiationis intrasset, foris non uideretur ulterius, nisi extrema transitus causa deportaretur ad cymiterium» (Vitae Patr. Iurens., 26: 266-267). Estos casos son excepcionales y pueden considerarse como unas prácticas poco frecuentes hasta el momento.

Como se ha apuntado líneas más arriba, son constantes las alusiones directas e indirectas en forma de recordatorio a la prohibición de salir del monasterio, el cual sólo podrían abandonar en caso de muerte: "si qua relictis parentibus suis saeculo renuntiare et sanctum ouile uoluerit introire, ut spiritalium luporum fauces deo adiuuante possit euadere, usque ad mortem suam de monasterio non egrediatur, nec in basilicam, ubi ostium ese uidetur» (Caes. Arel., Reg. uirg., 2, 3: 180). Se trata de una casuística que contrasta con la perseverancia reclamada a los hombres, sólo y exclusivamente en el primer capítulo, donde leemos: «in primis, si quis ad conuersionem uenerit, ea condicione excipiatur, ut usque mortem suam ibi perseueret» (Caes. Arel., Reg.mon., 1: 204); como puede observarse, en este último caso, el lenguaje y el tono utilizados dejan de tener ese cariz imperativo.

Con todo, y pese a los esfuerzos teóricos de los moralistas cristianos, el intento de constreñir la libertad de las mujeres a través del encierro no fue un sistema perfecto. Es decir, como el simple hecho de ser mujeres las incapacitaba para realizar trabajos propios del hombre, como podían ser la impartición de los sacramentos o todos aquellos oficios relacionados con el mantenimiento o el abastecimiento, no tuvieron más remedio que demandar estos servicios del exterior y contar con una determinada presencia masculina; por lo tanto, pudieron tener un cierto contacto con el mundo exterior. No obstante, esta cuestión no fue más que un cabo suelto con el que, por supuesto, contaba el autor de la Regula. Así pues, se observa cómo se regula la entrada de hombres al monasterio, siempre contando con el beneplácito de la abadesa, quien los acompañaría junto con otra testigo fiable (Caes. Arel., Reg. uirg., 36, 4-5: 218-220). El acceso a mujeres también quedó perfectamente regulado (Caes. Arel., Reg. uirg., 37: 220).

Dando una vuelta más de tuerca y moviéndonos — por el momento- en el terreno de la suposición, cabría preguntarse si estas tareas propiamente masculinas fueron en la mayoría de los casos ejercidas por hombres, o si por el contrario acabaron siendo las propias hermanas las que finalmente se hicieron cargo de algunas, o incluso de todas ellas (Wemple, 1981: 117), lo que, en definitiva, les hubiera permitido transgredir radicalmente los roles de género y ocupar puestos de control y poder que oficialmente les eran vetados. Hay diversas razones que motivan nuestras sospechas: primero, se sabe 
que Cesáreo no las visitaba con mucha frecuencia, cosa que lamenta en la carta Vereor: "et quia secundum sanctum uotum uestrum frequentius uso uisitare non ualeo» (Caes. Arel., Ep. ad sanctimon., 1, 3: 294-296); segundo, sabemos que las hermanas eran las responsables de la elección de los cargos de abadesa: "se domnes Christo inspirante unanimiter sanctam ac spiritalem eligite, quae et regulam monasterii possit efficaciter custodire, et superuenientibus responsum cum aedificatione et conpunctione et cum sancto affectu sapienter ualeat reddere» (Caes. Arel., Reg. uirg., 61 , 2: 244), del provisor y del sacerdote de la basílica funeraria de Santa María: "et hoc specialiter uolo, et ita domne episcope precor, ut siue prouisorem ad monasterium siue presbiterum ad basilicam sanctae Mariae nullum alium habeat congregatio sancta, nisi quem sibi ipsa elegerit uel ordinari petierit» (Caes. Arel., Test., 20: 386); pero, por si esto no fuera suficiente, Cesáreo se aseguró de mantener la independencia no sólo espiritual, sino también administrativa y financiera, prohibiendo a los futuros obispos de la ciudad cualquier tipo de injerencia en sus asuntos internos (Horm., Dilect. fratr. Caes., 1, 7-9: 354; 2, 3-4: 354-356 y Caes. Arel., Reg. uirg., 64, 1-3: 250). Vemos que en el caso de las hermanas de Arlés, éstas contaron con prerrogativas insólitas e inexistentes en otros cenobios femeninos.

No obstante, independientemente de cuáles fueran las prácticas reales ejercidas por mujeres, del mismo modo que el grado de cumplimiento del régimen de aislamiento, la voluntad de Cesáreo fue que la clausura en sus fundaciones fuera total, es decir, activa y pasiva (ni salir ni dejar entrar), independientemente del sexo de los individuos, o, al menos, en teoría: "mulieres in monasterio numquam ingrediantur, quia in remoto loco est» (Caes. Arel., Reg. mon., 11:210). No obstante, la clausura que fue requerida a los hombres lo fue en su forma más activa, no salir, y como se ha apuntado, se formuló más a modo de consejo que como exigencia.

Otra evidencia más de este tenaz sistema de clausura exigido a mujeres lo encontramos en la introducción de la figura de las posticiariae (Caes. Arel., Reg. uirg., 30: 208-210), unas mujeres que, a modo de guardianas, custodiaban la puerta del monasterio, una figura del todo ausente en la regla masculina y en otras reglas contemporáneas. La originalidad de su invención no la podemos atribuir al propio Cesáreo - a pesar de que Agustín (su principal fuente de inspiración) no las nombra en ninguno de sus escritos-, sino que ya estaban documentadas en fuentes antiguas (Courreau y Vogüé, 1998: 52), una prueba más de la gran erudición del obispo galo.

\section{Mecanismos de control masculino: la represión de la sexualidad femenina}

La cuestión central en torno a la cual giran todas aquellas especificidades y regulaciones que solamente van dirigidas a mujeres es la represión de su sexualidad, cosa que, como se aprecia, no ocurre en el caso de los hombres. Este control sexual ha sido utilizado his- 
tóricamente como una herramienta del poder masculino, como bien lo define Elizabeth Castelli (1986: 86): "a sign in the masculinist system of communication, a commodity in the system of Exchange»; además, y como señala la historiadora Franca Ela Consolino (1989: 35), "no esiste, né sul piano della teorizzazione, né su quello della precettistica, una produzione paragonabile per mole ed impegno a quanto si veniva scrivendo per le donne». Es por ello por lo que en este apartado se recogen todas aquellas regulaciones que están intrínsecamente ligadas con estas cuestiones, con la erradicación de la feminidad a través de la exigencia de la castidad, la exaltación de la virginidad, la regulación del peinado, del hábito o la higiene de esas mujeres devotas. La clausura es otro aspecto que también podríamos traer aquí a colación; no obstante, ésta ha sido analizada en detalle en el punto anterior. Habrá quien pueda considerar que la obediencia a preceptos como los de la castidad o el cumplimiento de un régimen de clausura estricta puedan ser exigibles a individuos de ambos sexos; no obstante, la exigencia de su cumplimiento impuesta al colectivo de mujeres, frente a las sucintas recomendaciones prescritas a los hombres, deja poco margen de dudas al respecto.

En referencia a la castidad, observamos que se trata de un tema recurrente en la epístola Vereor (ca. 512), aunque también la documentamos en la regla femenina (Caes. Arel., Reg. uirg., 23: 198-200), que recupera y además aumenta las prescripciones del Praeceptum de Agustín. Una insistencia y preocupación casi ausentes en el caso masculino, donde solamente se identifican dos alusiones a la castidad: "ad castitatis refrigerium peruenistis» (Caes. Arel., Reg.mon., 26, 5: 222) y "respuistis gulam, et abstinentiam elegistis» (Caes. Arel., Reg. mon., 26, 6: 222).

La materialización y el triunfo del mandato de la castidad femenina sólo se alcanzó a través del cumplimiento de los dos principales estados sexuales permitidos a las ascetas: los de virginidad y viudedad, que no tienen su equivalente en el masculino, lo que convertía estas cuestiones en algo genuinamente femenino (Caes. Arel., Reg. uirg., 5: 182-184). De hecho, esta especie de "estatus sexuales" gozaban de una aceptación generalizada y se prescribían a las mujeres en general, fueran o no religiosas. En el caso de las religiosas, esta era la vía más factible para que pudieran superar su supuesta inferioridad congénita, es decir, virilizándose (Consolino, 1989: 35) y asemejándose —no igualándose- en cierto modo a sus compañeros hombres, una opción impensable en el caso de mujeres seculares.

Cesáreo siguió en la línea de lo que ya hicieron sus predecesores y no escatimó esfuerzos en proteger el «objeto del deseo» que era el cuerpo femenino, considerándolo como algo susceptible de ser sexualmente agredido. El hábito monástico también tuvo sus utilidades en función de si se trataba de uno u otro sexo; así pues, los ropajes femeninos, a diferencia de los hombres, no ponían de manifiesto la autoridad de quien fuera que lo vistiese, sino que reflejaban su permanente estado de pecado (Juganaru, 2011: 12).

Es por ello por lo que Cesáreo atendió a la regulación de ciertos aspectos relativos al aspecto físico, como podían ser la eliminación de todo lo que representara belleza, el cuidado de la higiene o la vestimenta femenina. Así, por ejemplo, prescribió el tipo y el color del hábito (Caes. Arel., Reg. uirg., 22, 5: 198; 44, 1-3: 228; 55: 240), la altura y la forma 
del peinado: "capita numquam altiora ligent, quam in hoc loco mensuram de incausto fecimus" (Caes. Arel., Reg. uirg., 56: 240), o prohibió el baño en condiciones normales (Caes. Arel., Reg. uirg., 31:210).

\section{Conclusiones}

Las cuestiones examinadas a lo largo de estas páginas nos han planteado un amplio abanico de interrogantes que abren la puerta a nuevas posibles vías de investigación. A su vez, contamos con más datos que nos permiten no sólo ampliar, sino confirmar y dar solidez a aquello que ya se conoce sobre la configuración de la ideología y de la identidad de un colectivo concreto de mujeres en unas coordenadas espaciotemporales determinadas.

Además, el instrumento de la categoría analítica e identitaria del género no sólo nos ha permitido detectar los roles sociales atribuibles a mujeres y a hombres, y, por lo tanto, permitirnos un mayor conocimiento sobre los principios en los que se asentaba la identidad femenina en el mundo tardoantiguo, sino que también nos ha brindado la posibilidad de deconstruir y reinterpretar un discurso histórico que parecía universal, perenne y, por lo tanto, incuestionable.

Esto último no hace más que corroborar la urgente necesidad de revisión -y desnaturalización- de antiguos discursos y paradigmas que hemos venido asimilando e interiorizando como un dogma, así como también interpretar de forma crítica las fuentes desde los métodos de análisis que nos proporcionan las metodologías de investigación feminista.

Las potencialidades de incorporar estas técnicas a la investigación del pasado histórico son múltiples y traspasan los límites de la historia antigua, universal, e incluso de la academia; pero es que además son la mejor carta de presentación que nuestra cuestionada disciplina puede ofrecer a todos los desafectos, evidenciando que el conocimiento del pasado es imprescindible para comprenderse y repensarse, en un momento en que la sociedad necesita más espíritu crítico que nunca.

Como se colige de nuestro análisis, en primer lugar, e independientemente de cuáles fueran las causas que empujaron a Cesáreo a liderar la fundación femenina, el prelado arelatense se vio ante la necesidad urgente de legislar y de regular más allá de lo que podía estipular la lacónica Regula agustiniana, o incluso de la restricción impuesta por la Regula benedictina, ambas dirigidas a los ascetas por excelencia, los hombres; y esto se explica porque la condición sexual de sus futuras integrantes podía poner en serio peligro el prestigio de su comunidad y hacer tambalear los principios de la moral cristiana. Se observa, pues, cómo el encaje de la mujer suponía un reto y, a la vez, un mal necesario para los teóricos de la fe.

Aunque los testimonios conservados no nos concedan evidencias sólidas, resulta muy probable que las mujeres gozaran de ciertos márgenes de autonomía y capacidad de intervención en el seno de estas instituciones, tanto en las cuestiones temporales como en 
las espirituales, parece ser que sin recibir en exceso los resortes del dominio masculino. Autoras como Suzanne F. Wemple (1981: 177) fueron más allá e hicieron extensiva la autosuficiencia espiritual femenina al resto de monasterios galos que adoptaron la Regula de Cesáreo, dado que la falta de hombres aptos para celebrar la misa y la administración de los sacramentos seguramente empujó a las mujeres a ejercer como maestras.

Ahora bien, a pesar de estos supuestos conatos de libertad, las mujeres nunca pudieron gozar de plena autonomía en sus monasterios, dado que estaban inmersas en un sistema de parentesco espiritual en la cúspide del cual se situaba una figura masculina con autoridad sobre todas ellas y sus cuerpos (Rivera, 1989: 28), un hecho que documentamos blindado por ley por primera vez en el Concilio III de Cartago de 397, que estableció que tanto obispos como presbíteros ejercieran una custodia con las vírgenes como si fueran sus padres (Villegas, 2011:275). Baste mencionar aquí la figura del prouisor (Caes. Arel., Reg. uirg., 36: 218), una especie de mayordomo o asistente encargado del aprovisionamiento de las hermanas y de repartir el excedente del monasterio entre los más necesitados, unas competencias que bajo ninguna circunstancia debían ser ejercidas por mujeres.

No obstante, y aunque inmersas en este sistema de dominación y lógica masculina, las mujeres supieron adaptarse a las circunstancias y buscar los posibles resquicios donde poder evadir este control, incluso más allá de los límites terrenales, ya que según puede leerse en la ordenanza de la abadesa Cesárea o Constitutum — documento a modo de últimas voluntades que regulaba el aforo y las condiciones de entierro en la basílica funeraria de Santa María - se trataría de un lugar de reposo exclusivamente femenino, por lo que se prohibió la sepultura de amigos, patrones o servidores de la basílica, como sacerdotes o clérigos (Caesar. Abb., Const., 1-5: 496). No obstante, Cesáreo, contradiciendo la voluntad de su hermana y sobrepasando los límites del mundo terrenal, eligió el descanso eterno al lado de sus santas y venerables hijas.

En segundo lugar, y como se ha podido comprobar, el análisis comparativo y crítico de la documentación desde una perspectiva de género ha permitido identificar formas de relaciones sociales entre los sexos, roles e identidades impuestas y reproducidas con naturalidad en un determinado colectivo de mujeres. La férrea regulación sobre la clausura, la virginidad o la represión de la idea de belleza femenina no eran más que mecanismos para poder ejercer el control absoluto sobre los cuerpos de las mujeres, el verdadero quid de la cuestión; de lo que se trataba era de eliminar cualquier indicio de feminidad.

Los resultados de este trabajo sitúan en el debate historiográfico la conveniente $-\mathrm{y}$, si se me permite, la necesaria- utilización de perspectivas o métodos inclusivos en el análisis histórico, una metodología que a pesar de tener un amplio recorrido sobre sus espaldas no acaba de gozar del reconocimiento necesario para estar presente en todo tipo de análisis; para quienes trabajamos con el género, éste nos resulta indisociable de cualquier estudio o investigación que se tercie, ya sea histórico o actual, ya que para ser rigurosas, las mujeres han sido y son, al igual que sus compañeros de andanzas, actores imprescindibles y fundamentales del devenir histórico. 


\section{Nota}

El presente artículo ha sido realizado en el marco de la concesión de una ayuda para contratos predoctorales para la Formación del Profesorado Universitario del Ministerio de Ciencia, Innovación y Universidades FPU18/06126 y se enmarca en los proyectos de investigación HAR2016-74981-P del Ministerio de Economía y Competitividad, cuyos investigadores principales son los profesores Josep Vilella y Juan Antonio Jiménez, y del GRAT (Grup de Recerques en Antiguitat Tardana), grupo de investigación de la Generalitat de Catalunya 2017SGR-211, dirigido por el profesor Josep Vilella Masana.

\section{Fuentes de tradición documental}

BEN(EDICTVS) ABB(AS CASINENSIS), Reg(ula) mon(achorum), ed. A. de VOGÜÉ, J. NEUFVILLE, Sources Chrétiennes, 181-182, París, 1972, 6 vol.

CAESAR(IA) ABB(ATISSA), Const(itutum), ed. A. de VOGÜÉ, J. COURREAU, Sources Chrétiennes, 345, París, 1988, 496-499.

CAES(ARIVS) AREL(ATENSIS), Ep(istula) ad sanctimon(iales), ed. A. de VOGÜÉ, J. COURREAU, Sources Chrétiennes, 345, París, 1988, 293-337.

CAES(ARIVS) AREL(ATENSIS), Reg(ula sanctarum) uirg(inum), ed. A. de VOGÜÉ, J. COURREAU, Sources Chrétiennes, 345, París, 1988, 171-273.

CAES(ARIVS) AREL(ATENSIS), Reg(ula) mon(achorum), ed. A. de VOGÜÉ, J. COURREAU, Sources Chrétiennes, 398, París, 1994, 204-227.

CAES(ARIVS) AREL(ATENSIS), Serm(ones), 233-238, ed. G. MORIN, Corpus Christianorum. Series Latina, 104, Turnhout, 1953, 925-953.
CAES(ARIVS) AREL(ATENSIS), Test(amentum), ed. A. de VOGÜÉ, J. COURREAU, Sources Chrétiennes, 345, París, 1988, 379-397.

Conc(ilium) Agath(ense), ed. C. MUNIER, Corpus Christianorum. Series Latina, 148, Turnhout, 1963, 189-228.

CYPR(IANVS), FIRM(INVS) ET VIV(ENTIVS), Vita (Sancti Caesari), ed. G. MORIN, vol. II, Maredsous, 1942, 296-345.

HORM(ISDAS), Dilect(issimo) fratr(i) Caes(ario), ed. A. de VOGÜÉ, J. COURREAU, Sources Chrétiennes, 345, París, 1988, 352-359.

PS(EVDO)-FRVCT(VOSVS EPISCOPVS) BRAC(ARENSIS), Reg(ula) com(munis), ed. J. CAMPOS, I. ROCA, Biblioteca de Autores Cristianos, 321, 1971, 172-211.

Vitae Patr(um) Iurens(ium), ed. F. MARTINE, Sources Chrétiennes, 142, París, 2004, 236-435. 


\section{Bibliografía}

ANDERSON, Elizabeth, 2010, Feminist

Epistemology and Philosophy of Science, Standord Encyclopedia of Philosophy [en línea]. Actualizado: 13 de febrero de 2020. Consulta: 22 de marzo de 2020. Disponible en https://plato.stanford.edu/ entries/feminism-epistemology/

AURELL, Jaume, 2005, La escritura de la memoria. De los positivismos a los postmodernismos, Valencia.

BARTRA, Eli, 2010, Acerca de la investigación y la metodología feminista, en Norma BLÁZQUEZ, Fátima FLORES y Maribel RÍOS (coords.), Investigación feminista. Epistemología, metodología y representaciones sociales, México D. F. (Debate y reflexión), 67-77.

BIGLIA, Bárbara, 2015, Avances, dilemas y retos de las epistemologías feministas en la investigación social, en Irantzu MENDIA (et al.), Otras formas de (re)conocer. Reflexiones, herramientas y aplicaciones desde la investigación feminista, DonostiaSan Sebastián, 21-44.

BROWN, Peter, 1993, El cuerpo y la sociedad. Los cristianos y la renuncia sexual, Barcelona [trad. A. J. Desmonts, The Body and Society: Men, Women and Sexual Renunciation in Early Christianity, 1990].

CASTELLI, Elizabeth, 1986, Virginity and its Meaning for Women's Sexuality in Early Christianity, Journal of Feminist Studies in Religion $1 / 2,61-88$.

CLARK, Elizabeth A., 1994, Ideology, History, and the Construction of "Woman" in Late Ancient Christianity, Journal of Early Christian Studies 2, 155-184.

CONSOLINO, Franca Ela, 1989, Il monachesimo femminile nella tarda antichità, Codex Aquilarensis 2, 1989, 33-45.

COURREAU, Joël y VOGÜÉ, Adalbert de (eds.), 1998, Césaire d'Arles. Euvres monastiques, vol. I: Euvres pour les moniales. Introduction, texte critique, traduction et notes, París (Sources Chrétiennes, 345).

COURREAU, Joël y VOGÜÉ, Adalbert de (eds.), 1994, Césaire d'Arles. Euvres monastiques, vol. II:
Euvres pour les moines. Introduction, texte critique, traduction, notes et index, París (Sources Chrétiennes, 398).

DELAGE, Marie-José, 1971-1986, Césaire d'Arles. Sermons au peuple, vol. I-III, París (Sources Chrétiennes, 175, 243, 330).

DELAGE, Marie-José, 2010, Vie de Césaire d'Arles. Texte critique de Dom G. Morin. Introduction, révision du texte critique, traduction, notes et index, París (Sources Chrétiennes, 536).

DERRIDA, Jacques, 1967, De la grammatologie, París.

DESPREZ, Vincent, 1980, Règles monastiques d'Occident. IVe-VIe siècle. D'Augustin à Ferréol, Bellefontaine (Vie monastique, 9).

ECKENSTEIN, Lina, 1896, Women under Monasticism: Chapters on Saint-lore and Convent Life between A.D. 500 and A.D. 1500, Cambridge.

GUZMÁN, Maricela y PÉREZ, Augusto R., 2005, Las Epistemologías Feministas y la Teoría de Género. Cuestionando su carga ideológica y política versus resolución de problemas concretos de la investigación científica, Cinta Moebio 22, 112-126.

HARDING, Sandra, 1987, ¿Existe un método feminista?, en Eli BARTRA (comp.), Debates en torno a una metodología feminista. Programa Universitario de Estudios de Género-UNAM, Xochimilco, 1998 (Ensayos), 9-34.

JUGANARU, Andra, 2011, From Social Death to Spiritual Rebirth. The Beginnings of Monastic Life for Christian Women between Late Antiquity and the Early Middle Ages (4th-6th Centuries), Cogito $3,1-16$

KELLY, Joan, 1990, ¿Tuvieron las mujeres Renacimiento?, en James S. AMELANG y Mary NASH (eds.), Historia y género: las mujeres en la Europa moderna y contemporánea, Valencia, 1990 (Estudios Universitarios, 38), 93-126.

KLINGSHIRN, William E., 1994, Caesarius of Arles. The Making of a Christian Community in Late Antique 
Gaul, Cambridge (Cambridge Studies in Medieval Life and Though, Fourth Series, 22).

MARTÍNEZ, Cándida, 2006², Los espacios de las mujeres hispanas, en Isabel MORANT (dir.), Historia de las mujeres en España y América Latina, vol. I: De la prehistoria a la Edad Media, Madrid, 153-192.

McCARTHY, Maria C., 1960, The Rule for Nuns of St. Caesarius of Arles: A Translation with a Critical Introduction, Baltimore (The Catholic University of America Studies in Mediaeval History, New Series, 16).

MIRÓN, María Dolores, 2010, Mujeres y poder en la Antigüedad clásica. Historia y teoría feminista, Saldvie 10, 113-125.

MORIN, Germain, 1942, Sancti Caesari episcopi Arelatensis opera omnia, vol. II, Maredsous.

RIVERA, María Milagros, 1989, Religiosidad para mujeres / religiosidad para hombres: sexo y género en el modelo monástico de Fructuoso de Braga (s. vII), en Ángela MUÑOZ (ed.), Las mujeres en el cristianismo medieval. Imágenes teóricas y cauces de actuación religiosa, Madrid, (Laya, 5), 19-30.

SCHULENBURG, Jane T., 1988, Female Sanctity: Public and Private Roles, ca. 500-1100, en Mary C. ERLER y Maryanne KOWALESKI (eds.), Women and Power in the Middle Ages, Georgia, 102-125.

SCHULENBURG, Jane T., 1989, Women's Monastic Communities, 500-1100. Patterns of Expansion and Decline, Signs 14/2, 261-292.
SESSA, Kristina, 2007, Christianity and the Cubiculum: Spiritual Politics and Domestic Space in Late Antique Rome, Journal of Early Christian Studies 15/2, 171-204.

TURBESSI, Giuseppe, 1974, Regole monastiche antiche, Roma (Testi e Documenti, 9).

VILLEGAS, Manuel, 2011, El monasterio de agustinas de Hipona (s. Iv-v) (Comunidad de oración y estudio), en Francisco Javier CAMPOS (coord.), La clausura femenina en el mundo hispánico: una fidelidad secular. Simposium (XIX Edición) San Lorenzo del Escorial, del 2 al 5 de septiembre, vol. I, Madrid, 267-287.

VOGÜÉ, Adalbert de, 1971, La Règle de Césaire d'Arles pour les moines: un résumé de sa Règle pour les moniales, Revue d'Ascétique et de Mystique 47, 369-406.

VOGÜÉ, Adalbert de, 1985, Les Règles monastiques anciennes (400-700), Turnhout, (Typologie des sources du Moyen Âge occidental, 46).

VOGÜÉ, Adalbert de, 1994, Césaire et le monachisme prébénédictin, en Dominique BERTRAND (et al.), Césaire d'Arles et la Christianisation de la Provence. Actes des journées "Césaire", París (Initiations aux Pères de l'Église), 109-132.

VOGUEL, Cyrille, 1964, Césaire d'Arles. Introduction et choix de textes, París (Témoins de la foi).

WEMPLE, Suzanne F., 1981, Women in Frankish Society. Marriage and the Cloister, 500 to 900 , Filadelfia. 